\title{
Artificial Insemination Service Efficiency and Constraints of Artificial Insemination Service in Selected Districts of Harari National Regional State, Ethiopia
}

\author{
Belayneh Engidawork \\ Haramaya University, Dire Dawa, Ethiopia \\ Email: asir97@gmail.com
}

How to cite this paper: Engidawork, B. (2018) Artificial Insemination Service Efficiency and Constraints of Artificial Insemination Service in Selected Districts of Harari National Regional State, Ethiopia. Open Journal of Animal Sciences, 8, 239-251.

https://doi.org/10.4236/ojas.2018.83018

Received: April 17, 2018

Accepted: July 2, 2018

Published: July 5, 2018

Copyright $\odot 2018$ by author and Scientific Research Publishing Inc. This work is licensed under the Creative Commons Attribution International License (CC BY 4.0).

http://creativecommons.org/licenses/by/4.0/

(c) $\underset{\mathrm{EY}}{\mathrm{C}}$ Open Access

\begin{abstract}
The study was conducted to evaluate efficiency of artificial insemination (AI) service and constraints of AI service selected Districts of Harar National Region State, Ethiopia. A total of 320 dairy cows were randomly selected from six districts of Harari region; Jin'Eala, Shenkor, Hakim, Dire-Teyara, Aboker, Sofi. Data on dairy cattle management, artificial insemination (AI) service efficiency and constraints of AI service were generated using structured and semi-structured questionnaire. Forty three straws of frozen semen was sampled from the regional AI service centre, thawed and evaluated at the region level for its quality (motility, viability and morphology) following standard procedures. The overall mean percentage of frozen semen motility at regional level was 49.6. Semen production period (batch) and Breed (exotic blood level) had no effect on frozen semen motility. The mean percentage of viable (live) spermatozoa was 58.3. Sperm viability was not significantly influenced by Semen production period (batch) and, breed (exotic blood level). The overall mean percentages of major and minor sperm morphological defects were 5.6 and 21.8, respectively. Frozen sperm major morphological defects were significantly affected $(p<0.05)$ by Semen production period (batch), however sire breed has no effect $(p>0.05)$ on frozen sperm major morphological defects. Frozen sperm minor morphological defects were not significantly affected $(P>0.05)$ by both semen production period (batch) and sire breed (exotic blood level). The mean number of service per conception (NSC) in the current study was found to be 1.6. It was not significantly affected by previous season of calving, previous year of calving and parity. Non-return rate value of Harari region AI service center was $48.1 \%$. Major constraints of
\end{abstract}


AI service delivery system in the study area were feed shortage, problem in heat detection, service charge for AI, distance from AI service centre and husbandry problem. Additional shortage of input for AI service activity particularly semen and liquid nitrogen was reported as constraint of artificial insemination service in the study area, which interrupt smooth delivery of AI service.

\section{Keywords}

Dairy, Smallholder, Semen, Estrus, Insemination

\section{Introduction}

Ethiopia possesses the largest livestock population compared to any country in Africa, nevertheless its productivity remains marginal [1]. In Ethiopia, genetic improvement through crossbreeding has been introduced through development and research projects during the last four decades. The distribution of crossbred heifers, the provision of artificial insemination service and setting up of bull service stations were major components of the development projects. As indicated by [2] through the effort of these projects, Ethiopia has built up a herd of more than 120 thousand cattle with exotic inheritance. However, since cattle breeding are mostly uncontrolled in Ethiopia, appropriate bull selection criteria have not been established applied and controlled which make genetic improvement difficult [3]. On the other hand, artificial insemination (AI), the most commonly used and valuable biotechnology [4] has been in operation in Ethiopia for over 30 years. Nevertheless, the efficiency and impact of the AI operation has not been well-documented [5]. Reproductive problems related to crossbreed dairy cows under farmers' conditions are immense [6]. Today AI was recognized as the primary tool for genetic improvement in cattle breeding. Therefore, a series of studies are needed to determine the coverage and performance of AI at national, provincial and district levels [7].

In Ethiopia almost all data used to evaluate breeding works so far are from government ranches or research stations. Besides, there were few field studies made to evaluate efficiency of artificial insemination (AI) service [8]. Nevertheless, they are not representative of the farming condition in the country [9]. Thus, since information collected from ranches and on stations are from controlled environment, it is difficult to figure out problems and enhance possible solutions on AI service efficiency and constraints of AI service at farmers level. On the other hand, artificial insemination services and its constraints are highly influenced by environmental factors, which call for studies under farmer management. Hence, the current study was initiated with the objectives of evaluating efficiency of artificial insemination service, and its limitations in selected districts of Harari National regional State, Ethiopia. 


\section{Materials and Methods}

\subsection{Description of the Study Areas}

The study was conducted in 6 districts of Harari region; Jin'Eala, Shenkor, Hakim, Dire-Teyara, Aboker, Sofi. The districts are among the nine districts of $\mathrm{Ha}-$ rari national regional State eastern Ethiopia. The Harari region is one of the nine administrative regions of Ethiopia. Harari National Regional State is located at a distance of $525 \mathrm{~km}$ eastern of Addis Ababa. The Harari region lies between latitude $9^{\circ} 24^{\prime} \mathrm{N}$ and $9^{\circ} 42^{\prime} 03^{\prime \prime} \mathrm{E}$ and $42^{\circ} 16^{\prime} \mathrm{E}$ longitude. The Harari region has a wet tropical and receives an annual rainfall between 600 and $900 \mathrm{~mm}$ in a bimodal pattern. The bimodal pattern is characterized by a short rainy season that occurs between March and April and a long rainy season that occurs between July and September [10] (Figure 1).

\subsection{Study Design}

The template is used to format your paper and style the text. Laboratory examinations of frozen semen were conducted to estimate frozen sperm motility, viability (live and dead cell count) and morphological defects. Besides, a cross-sectional type of study was carried out to assess, organization of artificial insemination (AI) service, methods of AI service delivery, price of AI service and challenges of AI service under smallholder dairy production system in the study areas. A semi-structured survey questionnaire, farm inspection and secondary data sources were used to collect the required information.

\subsection{Data Collection and Sampling Techniques}

A total of 43 straws of frozen semen were subjected to laboratory examination to analyze frozen semen quality. The sample size (43) is an appropriate range, since

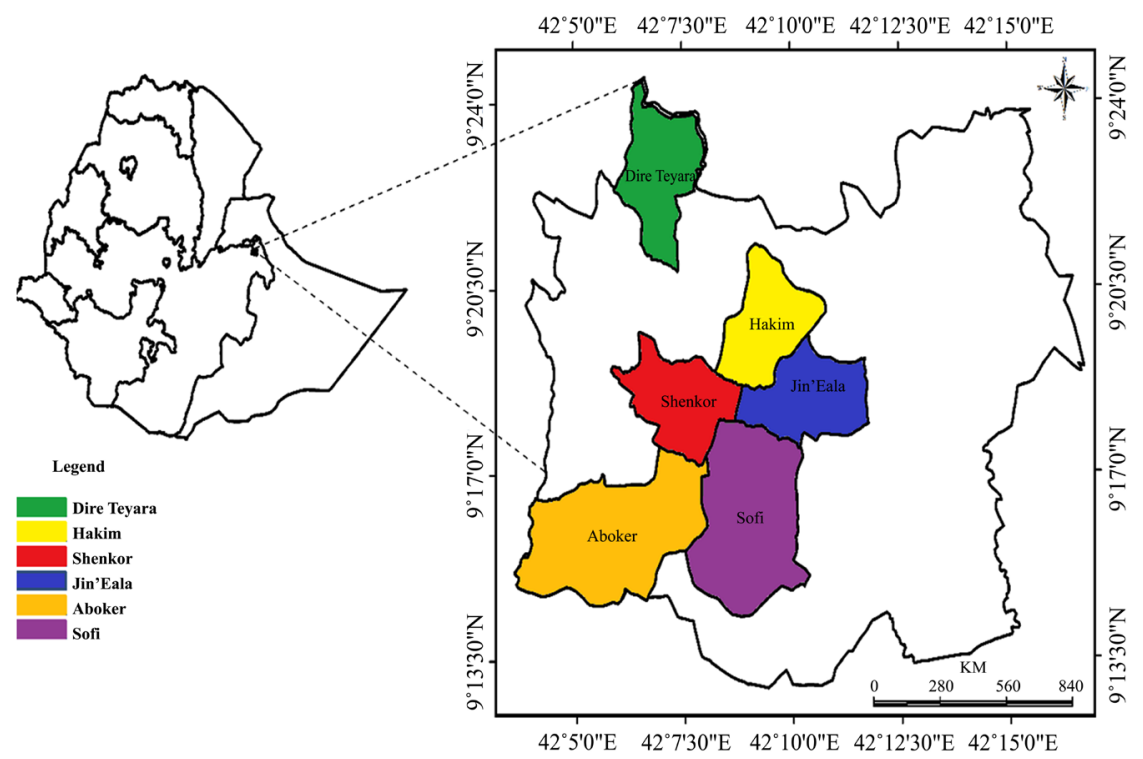

Figure 1. The map of the study districts. 
the range has sufficient statistical power and help to come up with correct decision on this particular research. The sample size is applicable to make more accurate decision and to minimize errors of the parameter estimate in the current study. The straws were randomly collected and examined to estimate frozen sperm motility, viability (live and dead cell count) and morphological defects. The frozen semen was composed of two breeds (100\% Holstein Friesian, and 75\% Holstein Friesian and 25\% Boran) and three production batches (B1 = batch code $15 / 163$ and production date $05 / 05 / 2015$; B2 = batch code $15 / 101$ and production date $07 / 05 / 2015 ; \mathrm{B} 3=$ batch code $15 / 100$ and production date $12 / 05 / 2015)$. Data on sperm quality at the site of production and processing was collected from record book at National AI center. Thus, loss of sperm quality was estimated as the difference between the two measurements. The laboratory examination procedures of semen were done in accordance with the procedures provided by [11] and [12]. Besides information regarding semen collection, processing and packing procedures was obtained from national artificial insemination center (NAIC) at Kaliti.

Sixty sample dairy producers (320 dairy cows) were selected from selected districts of Harari region. Sampled dairy producers are households who are living in the urban part of the study area, and provide very little or limited specialized inputs to their dairy enterprise. They sell fresh milk on a daily basis to private consumers. Excess milk is processed into butter and a local cottage cheese, ayib and sold in local markets, and used for domestic consumption. The system involves special inputs like artificial insemination and little supplementary feeds to roughages. Primary information was collected from targets household using structured and semi-structured questionnaires, observation and direct measurements. The survey was carried out across the milk shed to collect primary data using structured and semi-structured questionnaires, which were developed and pre-tested to check appropriateness and clarity of the questions. During the interview process, every respondent included in the study was briefed about the objective of the study before presenting the actual questions. Some of the information collected through interview was supported by observation.

\subsection{Data Analysis}

The collected data were computed using descriptive statistics. The General Liner Model procedure [13] and SPSS version 20 were used for analysis using the following models. Statistical measures that were used to summarize and categorize the research data were means, percentages and standard errors. Means were compared using Tukey adjustment. Models used were presented here under:

Model I: Analysis of frozen semen quality

$$
y_{i j} k=\mu+B_{j}+P_{k}+e_{j} k
$$

where: $y_{j} k=$ frozen semen quality (sperm motility, viability and morphology); $\mu$ $=$ Overall mean; $B_{j}=$ Effects of $j$ th Sire breed $(100 \%$ Holstein Friesian, and 75\% Holstein Friesian and 25\% Boran); $P_{k}=$ Effect of $k$ th Semen Production Period 
(B1= batch code $15 / 163$ and production date $05 / 05 / 2015 ; \mathrm{B} 2=$ batch code $15 / 101$ and production date $07 / 05 / 2015$; B3= batch code $15 / 100$ and production date $12 / 05 / 2015) ; e_{j} k=$ residual.

Model II: Analysis of number of service per conception (NSC)

$$
y_{j} k_{I}=\mu+G_{j}+S_{k}+P_{I}+e_{j} k_{l}
$$

where: $y_{j} k_{l}=$ trait (NSC); $\mu=$ over all mean; $G_{j}=$ effect of $j$ th previous calving year $(2013,2014,2015) ; S_{k}=$ effect of $k$ th previous calving season (short rainy season, dry season, long rainy season); $P_{l}=$ effect of th parity of dairy cows; $e_{j} k_{l}$ $=$ random error.

\section{Results and Discussion}

\subsection{Individual Progressive Motility of Frozen and Fresh Spermatozoa}

The values of fresh sperm individual progressive motility was obtained from national artificial insemination center (NAIC), where semen is collected processed and packed. The measurement was conducted immediately after the semen is collected. However, frozen sperm individual progressive motility was measured both at national artificial insemination center (NAIC) at the end of semen processing procedures and at the regional AI service center after transportation and further storage. Fresh semen individual progressive motility for all samples at the time of collection and processing at NAIC was $80 \%$ (Table 1). However motility of the same semen after freezing at the same center was $58.7 \%$, on average $21.3 \%$ loss due to freezing. After transportation and further storage at the regional AI service center, the average motility of frozen semen was further reduced to $49.4 \%$ (9.3\% loss). The loss happened might be through differences in chilling and freezing environment, including the volume and temperature of liquid nitrogen (storage) and transportation of semen from NAIC to regional AI service center. This is in general agreement with [14] and [15]. The report of [16] indicated that frozen semen below minimum recommended motility of $40 \%$ should be discarded, because it affects the efficiency of semen fertility. However, even though, the losses due to various factors explained above was substantial, frozen sperm progressive motility in the current study was slightly higher than the minimum recommended threshold.

Table 1. Individual progressive motility of fresh and frozen sperm $(\mathrm{N}=43)$.

\begin{tabular}{ccccc}
\hline \multirow{2}{*}{ Batch } & \multicolumn{4}{c}{ Individual progressive motility (\%) } \\
\cline { 2 - 5 } & Fresh semen at NAIC & $\begin{array}{c}\text { Frozen semen at } \\
\text { NAIC }\end{array}$ & $\begin{array}{c}\text { Frozen semen at } \\
\text { district }\end{array}$ & Motility loss \\
\hline B1 & 80 & 58 & $47.8 \pm 2.26$ & 10.2 \\
B2 & 80 & 63 & $49.1 \pm 1.23$ & 13.9 \\
B3 & 80 & 55 & $51.3 \pm 1.07$ & 3.7 \\
& 80 & 58.7 & 49.4 & 9.3 \\
\hline
\end{tabular}

$\mathrm{N}=$ number of observation; $(\mathrm{B} 1$ = batch code $15 / 163$ and production date $05 / 05 / 2015$; $\mathrm{B} 2$ = batch code $15 / 101$ and production date $07 / 05 / 2015 ; \mathrm{B} 3$ = batch code $15 / 100$ and production date $12 / 05 / 2015$ ). 


\subsection{Frozen Sperm Individual Motility and Viability}

Sperm individual motility can be defined as the percentage of all moving sperm in a semen sample. It is measured by placing a drop of semen on a slide using a light microscope under a cover slide at $400 \mathrm{x}$ magnifications (scored at $10 \%$ unit intervals). However viability is measurement of live and dead spermatozoa in a semen sample. Viable in its most basic sense means "live". Viability is measured using a light field microscope with an oil immersion lens at 1000X magnification, after letting the semen sample to be stained with eosin/nigrosin solution. Both Sperm individual Motility and Viability helps to figure out semen quality and they are presented in percentage. The overall regional mean of frozen semen progressive individual motility in the current study at was $49.6 \%$ (Table 2). The result is lower than $51.7 \%$ reported by [3] and $51.5 \%$ reported by [15], but higher than the result repotted by [14] which is $44.5 \%$. This variation might be due to differences in frozen semen handling practices, transportation, storage facilities and proximity of the region/district to National Artificial Insemination Center (NAIC). A study conducted by [16] indicated that if there are $40 \%$ or more of semen moving actively forward after freezing and thawing the quality is acceptable for artificial insemination, which is consistent with the current study. Both sire breed and batch (production period) had no effect $(P>0.05)$ on frozen semen motility.

The overall mean frozen semen viability at regional level was 58.3 (Table 2). The percentage of live spermatozoa observed in the current study was lower than (67.0\%) reported by [15] and higher than the result indicated by [14] that is $57.6 \%$. According to [16], for normal reproduction function, at least $50 \%$ of the frozen spermatozoa should be live, because each straw was initially packed with 30 million spermatozoa and at least half of this figure ( 15 million) is expected to be alive. The result of the current study indicated that frozen semen viability was

Table 2. Least squares mean $( \pm \mathrm{SE})$ frozen semen individual progressive motility and Viability.

\begin{tabular}{cccc}
\hline \multirow{2}{*}{ Variables } & \multicolumn{3}{c}{ Frozen semen progressive motility and viability (\%) } \\
\cline { 2 - 4 } & $\mathrm{N}$ & Motility (LSM \pm SE) & Viability (LSM \pm SE) \\
\hline Overall mean & 43 & $49.6 \pm 0.86$ & $58.3 \pm 0.77$ \\
Batch (production period) & & $\mathrm{ns}$ & $\mathrm{ns}$ \\
B1 & 12 & $47.8 \pm 2.26$ & $56.6 \pm 2.04$ \\
B2 & 14 & $49.1 \pm 1.23$ & $59.6 \pm 0.78$ \\
B3 & 17 & $51.3 \pm 1.07$ & $58.4 \pm 1.14$ \\
Sire breed & & $\mathrm{ns}$ & $\mathrm{ns}$ \\
$75 \%$ HF & 21 & $48.9 \pm 1.18$ & $58.5 \pm 1.13$ \\
$100 \%$ HF & 22 & $50.3 \pm 1.27$ & $58.1 \pm 1.06$ \\
\hline
\end{tabular}

$\mathrm{N}=$ number of observation; $(\mathrm{B} 1$ = batch code $15 / 163$ and production date $05 / 05 / 2015$; $\mathrm{B} 2$ = batch code $15 / 101$ and production date $07 / 05 / 2015 ; \mathrm{B} 3=$ batch code $15 / 100$ and production date $12 / 05 / 2015) ;{ }^{\star *}=P<$ $0.01 ;{ }^{\star} P<0.05 ; \mathrm{ns}=P>0.05$. 
not significantly $(P>0.05)$ affected by batch (production period) and sire breed. However, sperm viability recorded in this study, irrespective of the different effects, was higher than the minimum threshold of $50 \%$, below which conception was negatively influenced.

\subsection{Frozen Spermatozoa Morphological Defects}

The overall mean morphological defects of frozen semen at regional level were $27.4 \%$ (Table 3 ). Sire breed and Batch (production period) had no effect $(P>$ 0.05) on morphological defects of frozen spermatozoa. The differences in morphological defects between districts might be due to differences in semen handling, freezing and storage practices at different district AI service centers, and/or semen handling during transportation from NAIC to district AI service centers. There might be morphological defect variation among 75\% $\mathrm{HF}$ and $100 \%$ HF breed, since they have separate collection, processing and packaging procedures. However, breed had no significant effect on morphological defects of frozen spermatozoa.

The overall mean of major and minor morphological defect of frozen spermatozoa in the current study was $5.6 \%$ and $21.8 \%$, respectively (Table 3 ). The result obtained in the current study for major morphological defects were less than $6.5 \%$ reported by [3] and, greater than $4.8 \%$ and $4.3 \%$ reported by [14] and [15] respectively. The overall defects obtained in this study were slightly higher than the recommended overall major morphological defects, which is not more than $4 \%$ [16]. The same report indicated that the major morphological defects affect the AI delivery system through decreasing fertilizing ability of the post-thawed semen and by increasing the numbers of service per conception.

Table 3. Least squares means $( \pm S E)$ percent frozen sperm morphological defects $(N=43)$.

\begin{tabular}{|c|c|c|c|}
\hline \multirow[b]{2}{*}{ Variables } & \multicolumn{3}{|c|}{ Morphological defects (\%) } \\
\hline & $\begin{array}{c}\text { Overall defect } \\
(\mathrm{LSM} \pm \mathrm{SE})\end{array}$ & $\begin{array}{c}\text { Major defect } \\
(\mathrm{LSM} \pm \mathrm{SE})\end{array}$ & $\begin{array}{c}\text { Minor defect } \\
(\mathrm{LSM} \pm \mathrm{SE})\end{array}$ \\
\hline Overall mean & $27.4 \pm 0.85$ & $5.6 \pm 0.23$ & $21.8 \pm 0.79$ \\
\hline Batch & ns & * & ns \\
\hline $\mathrm{B} 1$ & $28.4 \pm 1.75$ & $6.1 \pm 0.36 \mathrm{a}$ & $22.3 \pm 1.74$ \\
\hline B2 & $26.4 \pm 1.48$ & $4.7 \pm 0.49 b$ & $21.7 \pm 1.39$ \\
\hline B3 & $27.5 \pm 1.36$ & $5.9 \pm 0.30 c$ & $21.6 \pm 1.18$ \\
\hline Breed & ns & ns & ns \\
\hline $75 \% \mathrm{HF}$ & $28.3 \pm 1.30$ & $5.6 \pm 0.27$ & $22.7 \pm 1.25$ \\
\hline $100 \% \mathrm{HF}$ & $26.5 \pm 1.13$ & $5.6 \pm 0.39$ & $21.0 \pm 0.98$ \\
\hline Mean normal spermatozoa & 72.6 & & \\
\hline
\end{tabular}


The current study indicated batch (semen production date) had significant effect $(P<0.05)$ on frozen semen major morphological defects. This variability might be due to differences in semen handling practices, transportation and freezing facilities. Pear shaped head, small abnormal head, detached abnormal head, acrosome defects, middle piece defects, tail stump, proximal droplet, strongly folded tail and narrow at the base are some of the common major sperm morphological defects recorded in the current study.

The percent of minor morphological defects recorded in this study was lower than $46.1 \%$ reported by [15], but the current result is higher than $20.9 \%$ which is reported by [14] and within the range of maximum minor morphological defect of $20 \%$ reported by [16]. Sire breed and semen production period) batch had a non-significant $(P>0.05)$ effect on minor morphological defects of frozen spermatozoa. The common minor morphological defects observed in the current study were simple bent tail, terminally coiled tail, abaxial implantation, detached normal head, giant broad head, and distal droplet (Table 4).

The mean frozen semen head morphological defect in the current stud was 4.7\%. The most common head defects in this study were pear shaped head, narrow at the base, abnormal counter, abaxial implantation, detached normal and abnormal head, giant broad head and acrosome defects.

The overall mean sperm mid-piece defect and tail morphological defects were $8.1 \%$ and $14.6 \%$ respectively. The result obtained in current study for head morphological defect, morphological defects of mid-piece and tail morphological defects were higher than $4.6 \%, 7.8 \%$ and $13.2 \%$ for head morphological defect, morphological defects of mid-piece and tail morphological defects respectively, which is indicated by [14]. Bent tail, tail stump and terminally coiled tail were common morphological defects found in this study.

In general, the overall mean frozen sperm morphological defects (27.4\%) are consistent with what has been recommended (25\%) for better conception rate.

Table 4. Least squares means $( \pm \mathrm{SE})$ percent frozen sperm morphological defects $(\mathrm{N}=43)$.

\begin{tabular}{cccc}
\hline & \multicolumn{3}{c}{ Morphological defects $\%)$} \\
\cline { 2 - 4 } Variables & $\begin{array}{c}\text { Head-defects } \\
(\mathrm{LSM} \pm \mathrm{SE})\end{array}$ & $\begin{array}{c}\text { Mid-piece-defect } \\
(\mathrm{LSM} \pm \mathrm{SE})\end{array}$ & $\begin{array}{c}\text { Tail-defect } \\
(\mathrm{LSM} \pm \mathrm{SE})\end{array}$ \\
\hline Overall mean & $\mathrm{ns}$ & $8.1 \pm 0.30$ & $14.6 \pm 0.84$ \\
Batch & $4.7 \pm 0.32$ & $\mathrm{~ns}$ & $\mathrm{~ns}$ \\
B1 & $4.4 \pm 0.27$ & $7.8 \pm 0.60$ & $15.9 \pm 1.66$ \\
B2 & $5.0 \pm 0.29$ & $8.2 \pm 0.56$ & $13.8 \pm 1.40$ \\
B3 & $\mathrm{ns}$ & $8.2 \pm 0.46$ & $14.2 \pm 1.40$ \\
Breed & $4.9 \pm 0.25$ & $7.9 \pm 0.38$ & $\mathrm{~ns}$ \\
$75 \%$ HF & $4.5 \pm 0.23$ & $8.1 \pm 0.47$ & $15.3 \pm 1.16$ \\
$100 \%$ HF & & ns & 1.22 \\
\hline
\end{tabular}

$\mathrm{N}=$ number of straw per sample; HF = Holstein Friesian; $(\mathrm{B} 1=$ batch code 15/163 and production date 05/05/2015; B2 = batch code 15/101 and production date $07 / 05 / 2015$; B3 = batch code $15 / 100$ and production date 12/05/2015); ns = non-significant; means with the same superscript are not significantly different $(P>0.05)$. 
In this study, the proportion of morphologically abnormal frozen spermatozoa was slightly higher (27.4\%) as compared to the maximum recommended level (25\%) for better conception rate. The mean percent sperm morphological head defects recorded in the current study was less than the recommended maximum value of $10 \%$, above which conception rate might be affected.

\subsection{Number of Services per Conception (NSC)}

The mean number of service per conception in this study was 1.60 (Table 5). The result is consistent with 1.6 services per conception reported in central highlands of Ethiopia [14] and [1]. However, the result was lower than 1.88 reported by [8] and 1.7 reported by [17] for smallholder crossbred dairy cows in north Gonder zone, Ethiopia and in and around Zeway, Ethiopia, respectively. Similarly, the present result is lower than 2.2 reported for crossbred cows [18]. Generally number of service per conception higher than 2.0 should be considered as poor [19]. Thus, the result reported in the current study can be considered as fairly good.

The result in the current study indicated that previous calving year had no significant effect $(P>0.05)$ on number of service per conception. Similar results were reported by Belayneh et al. (2013) and [8]. However, [20] and [21] reported a significant effect of year of calving on number of service per conception, which might be due to variation in AI technician efficiency, temperature, rainfall and feed supplementation, respectively. The report by [21] indicated that high environmental temperature and reduced efficiency of inseminators contribute to the higher rate of number of services per conception. Similarly, [22] reported a significance effect of previous calving year on number of service per conception.

Table 5. Least squares means $( \pm \mathrm{SE})$ Number of Service per Conception.

\begin{tabular}{ccc}
\hline Variables & \multicolumn{2}{c}{ Number of Service per Conception } \\
\cline { 2 - 3 } Over all Mean & $\mathrm{N}$ & LMS \pm SE NSC \\
\hline Previous calving season & 320 & $1.60 \pm 0.03$ \\
Short rainy season & & ns \\
Long rainy season & 80 & $1.55 \pm 0.07$ \\
Dry season & 116 & $1.61 \pm 0.05$ \\
Previous calving year & 124 & $1.65 \pm 0.06$ \\
2013 & & $1.60 \pm 0.10$ \\
2014 & 63 & $1.64 \pm 0.06$ \\
2015 & 126 & $1.58 \pm 0.05$ \\
Parity & 131 & ns \\
2 & & $1.62 \pm 0.06$ \\
3 & 87 & $1.69 \pm 0.06$ \\
4 & 127 & $1.55 \pm 0.07$ \\
5 & 72 & $1.41 \pm 0.09$ \\
\hline
\end{tabular}

$\mathrm{N}=$ number of observations, NSC $=$ number of service per conception; ${ }^{* *}=P<0.01 ;{ }^{* *}=P<0.001, \mathrm{~ns}=$ non-significant; means with the same superscript are not significantly different $(P>0.05)$. 
The same author also indicated that the variation was due to provision of bonus for each successful insemination they achieved and in later years this incentive was ceased and again reinitiated.

Number of services per conception was not significantly affected $(p>0.05)$ by previous calving season and parity. The finding was in general agreement with the study reported by [23] and [14]. Nevertheless, significant effect of parity of dam on number of service per conception was reported by [8] [24] [25] and [17].

\subsection{Non-Return Rate (NRR)}

The overall mean non-return rate to first inseminations in the current study was $48.1 \%$ (Table 6). The result obtained in this study is than $75 \%$ which is indicated by [14]. Similarly, [8] reported a non-return rate of $84.03 \%$ by analyzing the data of 6390 inseminations performed by four technician category in north Gondar Zone, Ethiopia. The variability on the value of NRR might be attributed to semen handling practices, AI technicians, and differences in semen quality used for insemination.

\subsection{Artificial Insemination (AI) Service Delivery System and its Constraint}

The most common AI service delivery system in the study area is mobile service delivery systems. It is a system in which AI technicians use motorcycles in order to visit smallholder dairy farms when informed by the owner through telephone on in person at their office. Generally there are two types of AI delivery systems in the study area: stationed and mobile service delivery systems. In stationery AI service delivery system, inseminators are stationed individually and farmers bring their cows to the insemination point. This is mostly practiced in the study area, and has been recommended as reported by [26] under the following conditions: when there is high cattle density in a particular area, when there is large commercial farm to employ the technicians, when it is not possible to provide the technician with means of transport due to financial reason. The other AI delivery system is a system in which AI technicians use motorcycles or car in order to visit $\mathrm{AI}$ crushes built along the main road in rural and peri-urban areas and known sites of the area.

Feed shortage, problem in heat detection, service charge for AI, distance from AI center and husbandry problem were the major constraints of AI service delivery system in the study area (Table 7). Similarly, [14] [27] and [28] reported

Table 6. Non-return rate $(\mathrm{NRR}(\mathrm{N}=320))$.

\begin{tabular}{cccccccccc}
\hline & \multirow{2}{*}{ Overall $\mathrm{N}$} & \multicolumn{2}{c}{$1^{\text {st }}$ insn } & \multicolumn{2}{c}{$2^{\text {nd }}$ insn } & \multicolumn{2}{c}{$3^{\text {rd }}$ insn } & NRR \\
\cline { 3 - 10 } & & $\mathrm{N}$ & $\%$ & $\mathrm{~N}$ & $\%$ & $\mathrm{~N}$ & $\%$ & \\
\hline Overall Performance & 320 & 154 & 48.1 & 114 & 44.1 & 20 & 6.3 & 48.1 \\
\hline
\end{tabular}

$\mathrm{N}=$ Number of observation; $\mathrm{NRR}=$ non return rate; insn = insemination. 
Table 7. Major constraint of AI service $(\mathrm{N}=60)$.

\begin{tabular}{ccc}
\hline & \multicolumn{2}{c}{ Proportion (\%) } \\
\cline { 2 - 3 } Variable (Constraint) & $\mathrm{N}$ & Percentage $^{*}$ \\
\hline Feed shortage & 56 & 93.3 \\
Problem in heat detection & 49 & 81.7 \\
Service charge for AI & 43 & 71.7 \\
Distance from AI center & 13 & 21.7 \\
Husbandry Problem & 8 & 13.3 \\
\hline
\end{tabular}

$\mathrm{N}=$ number of observation; ${ }^{*}=$ multiple responses were possible.

that heat detection, AI technicians' efficiency and fertility level of the herd was the most severe problems of AI delivery system. Additional shortage of input for AI activity particularly semen and liquid nitrogen was reported as constraint of artificial insemination service in the current study, which have an adverse effect on semen quality and reproductive performance of dairy cows.

In the current study, about $61.67 \%$ of AI beneficiary households (close to half) complained that they had a problem with regard to sex of the calves when they used artificial insemination. Thus, among these $61.67 \%$ households, about $83.78 \%$ reported that the tendency was higher for male sex than females. Since dairy farms are highly dependent on females for replacement and expansion purpose and thereby increase milk production, the current complaint of having more male calf than females deserves further research.

\section{Conclusion}

Generally, the overall observed efficiency of artificial insemination service under smallholder dairy cow's management system in the study area was fairly good. Hence, coverage of the AI service and the ongoing activities to improve and expand provision of liquid nitrogen and semen with appropriate exotic blood level at smallholder level in the area should be encouraged. However, shortage of feed, inadequate heat detection practices, service charge for AI, long distance from AI center, and poor management of animals are identified as major constraints of AI services in the current study.

\section{Acknowledgements}

The author is thankful to Haramaya University for funding the research work; artificial insemination technicians and dairy farmers of Jin'Eala, Shenkor, Hakim, Dire-Teyara, Aboker, Sofi districts and Harari Region Office of Livestock Resource and Fisheries for providing all necessary information/facilities during the course of the study.

\section{References}

[1] Yohaness, S., Tenhagn, B.A., Bekana, M. and Teshager, K. (2003) Reproductive 
Performance of Crossbred Dairy Cows in Different Production Systems in the Central Highlands of Ethiopia. Tropical Animal Health and Production, 25, 551-561.

[2] Ahmed, M.M., Bezabih Emana, M.A., Tangka, J.F. and Ehui, S. (2003) Economic and Nutritional Impacts of Market-Oriented Dairy Production in the Ethiopian Highlands. Socio-Economics and Policy Research Working Paper 51. ILRI (International Livestock Institute), Nairobi, 27.

[3] Gebremedhin, D. (2008) Assessment of Problems/Constraints Associated with Artificial Insemination Service in Ethiopia. M.Sc. Thesis, Addis Ababa University, Debre Zeit.

[4] Webb, D.W. (2003) Artificial Insemination in Cattle. University of Florida, Gainesville, IFAS Extension, DS 58, 1-4.

[5] Himanen, A. and Tegegn, A. (1998) A Proposal for Establishment of a National Milk Recording and Herd Registration Scheme in Ethiopia. Ministry of Agriculture, Addis Ababa.

[6] Tadesse, B. (2005) Calf Sex Ratios in Artificially Inseminated and Natural Mated Female Crossbred Dairy Herd. Proceedings of the 13th Annual Conference of the Ethiopian Society of Animal Production, Addis Ababa, 225-230.

[7] NAIC (1995) Ministry of Agriculture. National Artificial Insemination Center Addis Ababa, Ethiopia.

[8] Abate, H. (2008) Evaluation of Artificial Insemination Service Efficiency and Reproductive Performance of F1 Friesian Crosses in North Gonder Zone, Ethiopia. M.Sc. Thesis, Alemaya University, Haramaya.

[9] Haile Mariam, M. (1994) Genetic Analysis of Boran, Friesian, and Crossbred Cattle in Ethiopia. PhD Thesis. Swedish University of Agricultural Sciences, Uppsala, 59-112.

[10] CSA (2016) (Central Statistical Authority) Agricultural Sample Survey Statistical Bulletin. Central Statistical Authority, Addis Ababa.

[11] Oscar, A. (2003) Comparison of Three Oestrus Detection Systems during Summer Heat Stress in a Large Commercial Dairy Herd.

[12] Bearden, H.J. and Fuquary, J.W. (2004) Applied Animal Reproduction. 5th Edition, Prentice Hall Inc., Upper Addles, 138-147.

[13] SAS (2008) Statistical Analysis System. SAS User Guide, Statistics. SAS Institute Inc., Cary.

[14] Engidawork, B., Mekasha, Y. and Kebede, K. (2013) Evaluation of Artificial Insemination Service Efficiency and Reproductive Performance of Crossbred Dairy Cows in North Shewa Zone, Ethiopia. M.Sc. Thesis, School of Animal and Range Sciences, School of Graduate Studies of Haramaya University, Haramaya.

[15] Amare, T. (2010) The Status and Constraints of Artificial Insemination in Cattle in the Three Selected Districts of Western Gojjam Zone of Amhara Region, Ethiopia. M.Sc. Thesis, The Department of Animal Production and Technology, School of Graduate Studies of Bahir Dar University, Bahir Dar.

[16] IAEA and FAO (2005) Improving Artificial Breeding of Cattle in Africa Guidelines and Recommendations.

[17] Yifat, D., Kelay, B., Bekana, M., Lobago, F., Gustafsson, H. and Kindahl, H. (2010) Study on Reproductive Performance of Crossbred Dairy Cattle under Smallholder Conditions in and around Zeway, Ethiopia. Livestock Research for Rural Development, 21. 
[18] Mureda, E. and Zeleke, Z.M. (2007) Reproductive Performance of Crossbred Dairy Cows in Eastern Lowlands of Ethiopia. M.Sc. Thesis, The Department of Animal Sciences, School of Graduate Studies of Haramaya University, Haramaya.

[19] Mukasa-Mugerwa, E. and Tegegne, A. (1991) Reproductive Performance in Ethiopia Zebu (Bos indicus) Cattle: Constraint and Impact on Production. Proceeding on the 4th National Livestock Improvement Conference, Addis Ababa, 13-15 November 1991, 16-28.

[20] Tegegne, A. (1981) Reproductive Performance or Zebu and Crossbred Cattle in Ethiopia. M.Sc. Thesis, Addis Ababa University, Addis Ababa.

[21] Swensson, C.J., Schar, L.B., Brannag, E. and Meskel, L.B. (1981) Breeding Activities of the Ethio-Swedish Integrated Rural Development Project. Part 3. Reproductive Performance of Zebu and Crossbred Cattle. World Animal Review, 38, 31-36.

[22] HaileMariam, M. (1987) Evaluation of Growth and Reproductive Performance of Borana Cattle and Their Crosses with Friesian at Abernossa, Ethiopia. M.Sc. Thesis, Alemaya University of Agriculture, Dire Dawa.

[23] Njubi, D., Rege, J.E., Thorpe, W., Collins Lusweti, E. and Nyambaka (1992) Genetic and Environmental Variation in Reproductive and Lactation Performance of Jersey Cattle in the Coastal Lowland Semi-Humid Tropics. Tropical Animal Health and Production, 24, 231-244.

[24] Enyew, N., Brannang, E. and Rotmann, O.J. (2000) Reproductive Performance and Herd Life of Crossbred Dairy Cattle with Different Levels of European Inheritance in Ethiopia. Proceedings of 7 th Annual Conference of the Ethiopian Society of Animal Production, Addis Ababa, 26-27 May 1999, 65-75.

[25] Afewarke, Y., Tegegne, A. and Kassa, T. (2001) Reproductive Performance of Crossbred Dairy Cows at Asella Livestock Research Station, Arsi, Ethiopia. Ethiopia Journal of Animal Production, 1, 1-12.

[26] NAIC (National Artificial Insemination Center) (1999) Annual Report. Kality.

[27] Damron, W.S. (2000) Introduction to Animal Science: Global, Biological, Social and Industry.

[28] Barrett, M.A. and Larkin, P.J. (1974) Milk and Beef Production in the Tropics. Oxford University Press, ELY House, London, Volume 1. 